\title{
Durability assessment of heritage architecture
}

\author{
M. Holický \& J. Marková \\ CTU in Prague, Klokner Institute, Czech Republic
}

\begin{abstract}
General principles on durability assessment are provided in a newly developing international standard ISO "General Principles on the Design of Structures for Durability" prepared by an international working group of experts. It is expected that the document will soon be completed and then implemented into the systems of national standards in many countries. The document can be used in durability assessment of any building including heritage architecture. However, the operational use of the new procedures in practice would require additional studies focussed primarily on durability criteria, physical models of material deterioration, and theoretical models of basic variables. It appears that the probabilistic methods may provide valuable background information facilitating specification of appropriate durability criteria.
\end{abstract}

Keywords: durability, service life, limit states, target probability, architecture.

\section{Introduction}

The Technical Committee TC 98 of the International Organisation for Standardisation ISO prepares a new document on structural design (ISO 13823 [1]) provisionally entitled "General Principles on the Design of Structures for Durability". It is foreseen that the document will be used for durability assessment of buildings from different materials including heritage architecture. The document is based on fundamental principles provided in recent international documents (ISO 2394 [2], ISO 19338 [3] and EN [4]). Materials of other international organisations (CEB [5] and RILEM [6] and Fib [7]) and number of publications ([8] to [13]) are also taken into account. Other references to ISO/IEC materials and to particular studies are given in the upcoming document ISO 13823 [1].

Experts participating in the development of the document ISO 13823 [1] come from different countries of the whole word. International discussions of 
methodical principles (including terminology) have been therefore very complicated and time consuming. In spite of that the document is at present in an advance stage of development and it is expected that it will be completed and agreed by the Technical Committee TC 98 within a year. Then the Committee Draft (CD) will be submitted to the secretariat of ISO for further processing. After its publication the document will be most likely implemented into the national systems of standards in many countries. However, the process of implementation will not be easy and would definitely require additional research and development.

Submitted contribution points out some deficiencies of the present version, indicates expected difficulties in operational use of the document and specifies topics required for further research and development.

\section{Contents of the upcoming ISO document}

Current draft of the document ISO 13823 [1] has 10 Chapters (denoted by numbers 1 to 10) and 6 Annexes (labelled by letters A to F):

1. Scope

2. Application

3. Normative references

4. Terms and definitions

5. Symbols

6. Performance concepts for durability

7. Durability requirements

8. Design service life of the structure and its components

9. Predicted service life

10. Strategies for durability design

A. Examples of the applications of the limit states method

B. Examples of environmental actions and agents

C. Examples of transfer mechanisms

D. Environmental actions for structural materials and their control

E. Procedures for assuring durability

F. References

At present the whole document ISO 13823 [1] has 35 pages and includes general concepts as well as a number of practical provisions. The following text is however limited to the critical review of the conceptual Chapters 6 and 7, and Annex A.

\section{Limit states concept}

Chapter 6 of the document ISO 13823 [1] entitled "Performance concepts for durability" formulates principles of limit state methods for durability. The key steps of the deterioration processes and reliability verification using concepts of limit states are indicated in Figure 1. 
It should be noted that Figure 1 is a result of many discussions and amendments made during development of the document ISO 13823 [1] and it might still be altered. It is however a very general and simplified scheme that could be in a particular application modified depending on the actual conditions.

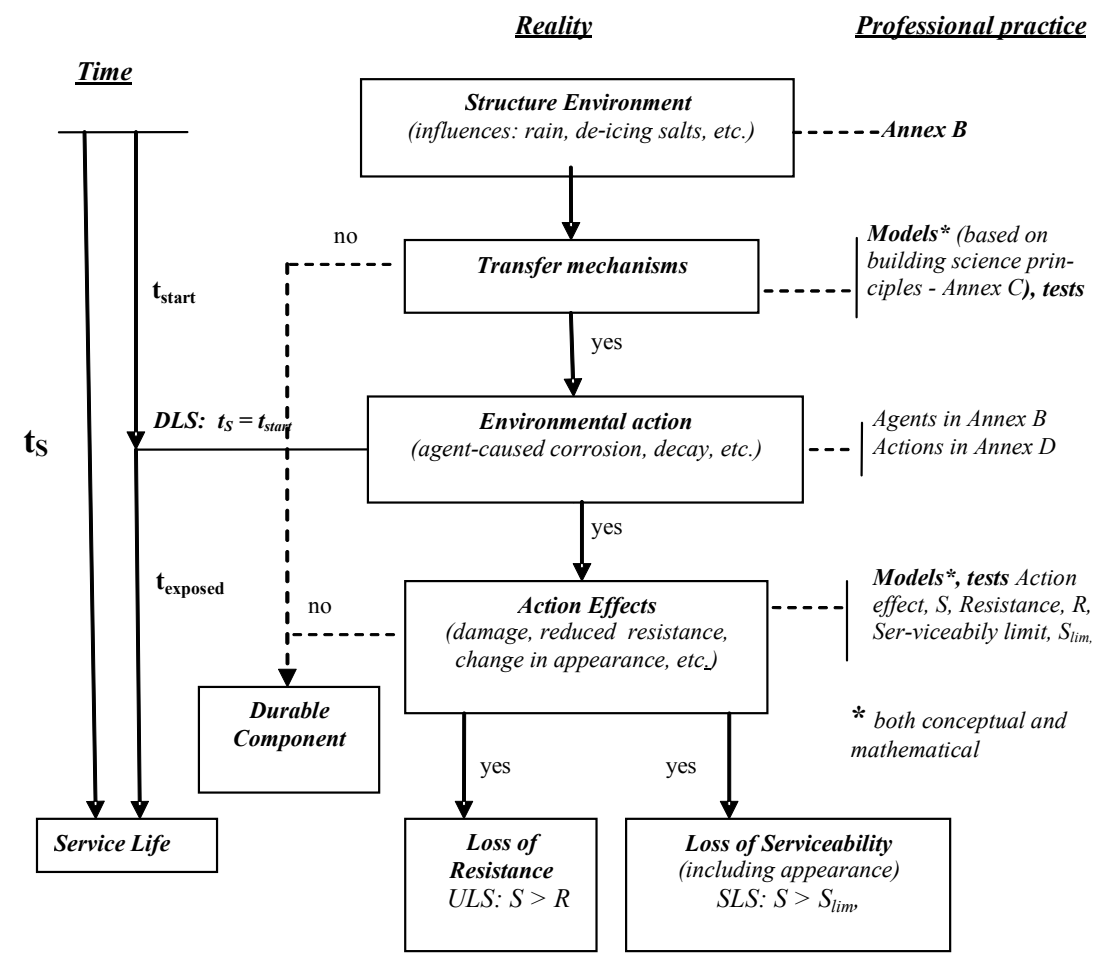

Figure 1: $\quad$ Limit states method for durability.

There are three vertical parts in Figure 1: time axis on the left, reality in the middle and professional practice on the right. The time axis is split into two parts by a point denoted as Durability Limit State (DLS). The term "Durability Limit State" is adopted from another ISO document (ISO 19338 [3]). It corresponds to the point in time when environment actions (development of unfavourable processes) have turning point (for example beginning of reinforcement corrosion or decay of construction materials). In case of carbonation it is a point when neutralized carbonation depth reaches reinforcement surface and corrosion may start (see an example given in below 5). This is a point in time denoted as the Durability Limit States DLS.

The middle part of Figure 1 indicates a sequence of real processes: "Structural Environment" and influences (rain, de-acing salts and other agents), "Transfer 
mechanisms" of environmental influences and "Environmental effects" (reinforcement corrosion, material decay). On the right in Figure 1 it is indicated that transfer mechanisms may be described by models or tests. Two types of models are generally distinguished: Conceptual (heuristic) specified on the bases of reasoning and previous experience and mathematical (analytical) specified on the basis of theoretical assumptions, for examples concerning diffusion processes.

Environmental effects may in general be combined with action effects (the middle part of Figure 1). Resulting effects may then lead to the loss of resistance (bearing capacity) of structures or to the loss of serviceability (excessive width of cracks or deformation). These limit states ULS and SLS are indicated in the lower part of Figure 1. An important question of load combination rules is however in the document ISO 13823 [1] not covered.

\section{Verification of the service life}

The fundamental durability requirement is represented by a simple condition that the predicted service life $t_{\mathrm{SP}}$ should be greater than the design service life $t_{\mathrm{D}}$ with sufficient degree of reliability. Difficulties are obviously linked to the term "sufficient reliability". It is well recognised that the service life $t_{\mathrm{S}}$ is dependent on a number of basic variables and is consequently a random variable having a considerable scatter. The document ISO 13823 [1] therefore provides a probabilistic formulation of this criterion in the form

$$
\mathrm{P}\left\{t_{\mathrm{S}}<t_{\mathrm{D}}\right\}<P_{\text {target }}
$$

Here $P_{\text {target }}$ denotes the target probability, that the service life $t_{\mathrm{S}}$ is less than design service life $t_{\mathrm{D}}$. As a rule the design service life $t_{\mathrm{D}}$ is a deterministic quantity (commonly 50 or 100 years, in case of heritage architecture it may be a longer period) specified in advance.

\section{Verification of the limit states}

Probabilistic formulation of the limit states conditions is similar as in case of service life. For an arbitrary point in time $t \leq t_{\mathrm{D}}$ the following condition should be valid

$$
\mathrm{P}_{\mathrm{f}}(\mathrm{t})=\mathrm{P}\{R(t)-S(t)<0\}<P_{\text {target }}
$$

where $R(t)$ denotes resistance and $S(t)$ action effect.

The basic probabilistic condition for the serviceability may be written analogically as

$$
\mathrm{P}_{\mathrm{f}}(t)=\mathrm{P}\left\{S_{\text {lim }}-S(t)<0\right\}<P_{\text {target }}
$$

Here $S_{\text {lim }}$ denotes the limit value of the serviceability indicator (for example of the crack width or deflection). The durability limit state (DLS) may be verified in accordance with eqn (2) or (3) depending on the particular conditions. 
Probabilistic assessment of the service life $t_{\mathrm{SP}}$ is schematically shown in Figure 2, which has been similarly as Figure 1 many times discussed and modified. It should be emphasized that Figure 2 describes only monotonously varying load effects $S(t)$ and resistances $R(t)$. The horizontal axes denotes the time $t$ and the vertical axes in the upper part the resistance $R(t)$ or in the lower part the load effect $S(t)$. Probability distributions of variables $R(t)$ and $S(t)$ are in Figure 2 indicated by probability density functions.

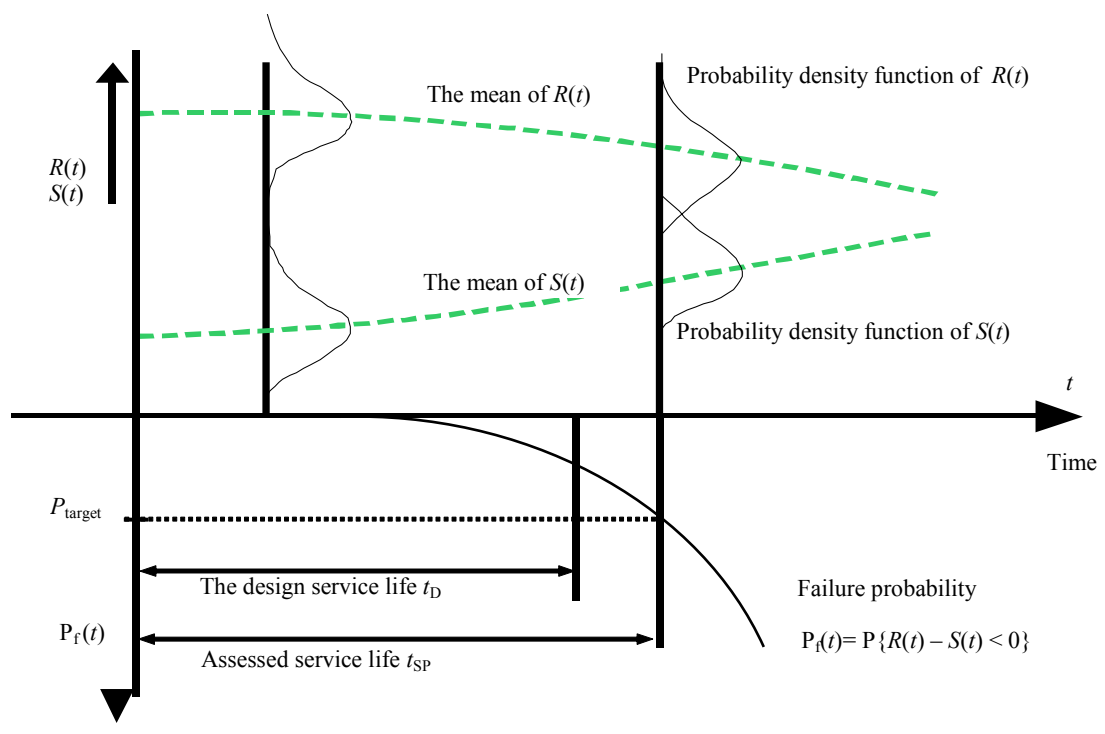

Figure 2: $\quad$ Probabilistic assessment of the service life.

Obviously the failure probability $\mathrm{P}_{\mathrm{f}}(t)=\mathrm{P}\{R(t)-S(t)<0\}$ is an increasing function time $t$. The assessment $t_{\mathrm{SP}}$ then follows from the relationship

$$
\mathrm{P}_{\mathrm{f}}\left(t_{\mathrm{SP}}\right)=\mathrm{P}\left\{R\left(t_{\mathrm{SP}}\right)-S\left(t_{\mathrm{SP}}\right)<0\right\}=P_{\text {target }}
$$

However, the document ISO 13823 [1] does not offer any guidance concerning the target probability $P_{\text {target }}$. This question remains open.

\section{Target probability}

Target reliability level, indicated by the target probability $P_{\text {target }}$ or reliability index $\beta_{\text {target }}$, depends in general on the definition of the service life time, whether the critical durability requirement concerns the ultimate limit state, serviceability limit state or durability limit state and are consequences of their infringement. In particular conditions the target reliability level may considerably vary. Table 1 provides indicative values (intervals) for the target probability $P_{\text {target }}$ and the reliability index $\beta_{\text {target }}$. 
Table 1: $\quad$ The target probability $P_{\text {target }}$ and reliability index $\beta_{\text {target }}$.

\begin{tabular}{|l|c|c|}
\hline Limit state & $P_{\text {target }}$ & $\beta_{\text {target }}$ \\
\hline Ultimate limit state - ULS & $\sim 10^{-4}$ & $\sim 3,7$ \\
\hline Serviceability limit state - SLS & 0,01 to 0,10 & 1,3 to 2,3 \\
\hline Durability limit state - DLS & 0,05 to 0,20 & 0,8 to 1,6 \\
\hline
\end{tabular}

The target probability $P_{\text {target }}$ and reliability index $\beta_{\text {target }}$ given in Table 1 represent indicative values only. They are derived from target values recommended in ISO 2394 [2] and EN 1990 [4]. It should be mentioned that ISO 2394 [2] indicates additional dependence of target values on relative costs of safety measures (required for an increase of the reliability level). This aspect should be also considered when specifying target reliability level for durability requirements. Specification of the appropriate reliability level remains therefore one of the most important open questions, particularly in case of heritage architecture.

\section{An example of the durability limit state}

The durability limit state DLS can be well illustrated by carbonation of the concrete. The limit state is defined as a simple requirement that the carbonation depth $S(t)$ (load effect) is less than the concrete cover $R$ (resistance). Failure probability can be then determined using eqn (2) from the integral

$$
P_{\mathrm{f}}(t)=P\{S(t)>R\}=\int_{-\infty}^{\infty} \varphi_{S}(x, t) \Phi_{R}(x) \mathrm{d} x
$$

where $\varphi_{S}(x, t)$ denotes probability density function of the load effect $S(t)$ and $\Phi_{R}(x)$ distribution function of the resistance $R$ (Holický and Mihashi [11]).

Extensive measurements of the carbonation depth $S(t)$ on cooling towers (Holický et al. [11] and [13]) (unprotected external concrete) provided the following expressions for the mean $\mu_{S}(t)$, coefficient of variation $w_{S}(t)$ and skewness $\alpha_{S}(t)$

$$
\mu_{S}(t)=5 t^{0,2} \mathrm{~mm}, w_{S}(t)=0,1 t^{0,2}, \alpha_{S}(t)=0,2 t^{0,2}
$$

where $t$ denotes time in years. Gamma distribution seems to be the most suitable theoretical model. For time invariant concrete cover the following parameters have been obtained

$$
\mu_{R}=20,25 \text { a } 30 \mathrm{~mm}, w_{R}=0,35 \mathrm{~mm}, \alpha_{R}=0,35
$$

In that case Beta distribution having the lower bound at zero seems to be the appropriate theoretical model. Note that in Annex A of ISO 13823 [1] a normal distribution is assumed for both variables $S(t)$ and $R$; this assumption may, in general, provide a first approximation only. 
Considering the above mentioned theoretical models and their parameters given in eqn (6) and (7) the failure probability $P_{\mathrm{f}}(t)$ given by eqn (5) is shown in Figure 3 that can be used to assess the service life $t_{\mathrm{SP}}$ defined by eqn (4) for specified target probability $P_{\text {target }}$ and the mean of concrete cover $\mu_{R}$. If, for example, $P_{\text {target }}=0,10$, then the mean $\mu_{R}=20 \mathrm{~mm}$ corresponds to $t_{\mathrm{SP}} \sim 23$ years, if $\mu_{R}=30 \mathrm{~mm}$ then $t_{\mathrm{SP}} \sim 65$ years. Figure 3 confirms results of previous studies by Holický et al. [11, 13], which indicates that assessment of $t_{\mathrm{SP}}$ is significantly dependent on theoretical models assumed for $R(t)$ and $S(t)$, and on specified target probability $P_{\text {target }}$. It appears that specification of the target reliability level can be solved using methods of probabilistic optimisation ([11-13]).

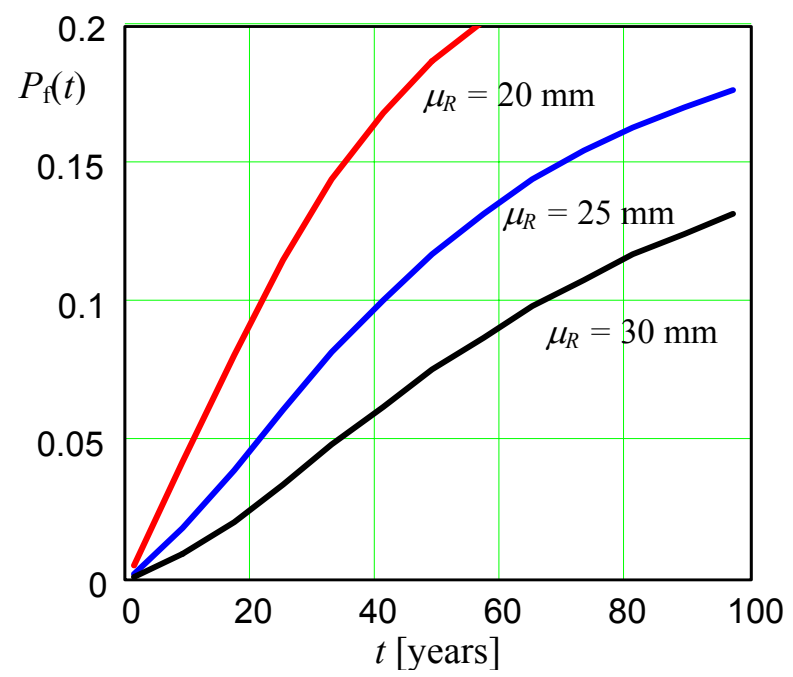

Figure 3: $\quad$ Probability $\mathrm{P}_{\mathrm{f}}(t)$ for parameters given in eqn (6) and (7).

\section{Concluding remarks}

Probabilistic principles of structural design for durability may be soon codified in the International Standard ISO. It appears, however, that assessment of service life is strongly dependent on the theoretical models of basic variables and specified reliability level. The target reliability levels should be differentiated taking into account the character of the building or heritage architecture and the limit state, consequences of durability failure and costs of safety measures to increase the reliability level. Methods of probabilistic optimisation may provide rational background information for specification of the target reliability level.

Operational use of the new procedures in assessment of common buildings and heritage architecture requires further research that should be primarily focussed on the following topics: 
- Appropriate physical models for material deterioration

- Suitable theoretical models for basic variables

- Differentiated probabilistic criteria for durability requirements.

\section{Acknowledgement}

This study is a part of research project GAČR 103/06/1562 "Development of durability concepts for verification of structures and materials".

\section{References}

[1] ISO 13823 General Principles on the Design of Structures for Durability. ISO TC98/SC2. Draft 10. 2006.

[2] ISO 2394 General principles on reliability for structures. ISO 1998.

[3] ISO 19338 Performance and assessment requirements for design on structural concrete. 2003.

[4] EN 1990 Eurocode - Basis of structural design. CEN 2002.

[5] CEB Bulletin d' Information No. 238 New Approach to Durability Design. An example for carbonation induced corrosion. (1997).

[6] RILEM REPORT 14 Durability Design of Concrete Structures, Edited by Sarja A. and Vesikari E., E \& FN SPON, London (1997).

[7] Fib TG 5.6: Model Code for Service Life Design (SLD), working material. 2004.

[8] Sarja, E. Vesikari, eds.: Durability design of concrete structures. RILEM Report Series 14, E\&FN Spon, vol.VI, 1997, pp. 165

[9] Norami T.: Service life design. Construction and Building Materials, vol.10, no 5, 1996, pp. 403-406

[10] Teplý, B.: Mezní stavy včera, dnes a zítra (The limit states today and in future). Stavebni obzor 7/2005, pp. 193-196.

[11] Holický M. and Mihashi H.: Stochastic Optimisation of Concrete Cover Exposed to Carbonation. In: R.E. Melchers \& Mark G. Steward (ed.), Application of Statistics and Probability. A. A. Balkema Rotterdam (2000), pp. 279-284.

[12] Holický M. and Holická N.: Probabilistic optimisation of concrete cover exposed to carbonation. Proc. of the International RILEM-JCI Seminar. pp. 384-393. RILEM 2006.

[13] Holický, M.: Probabilistic verification and optimization of structural durability. ICASP 2007, Tokyo, to be published. 